\title{
Sustainable Catalytic Conversion of Biomass for the Production of Biofuels and Bioproducts
}

\author{
Gabriel Morales *(D), Jose Iglesias *(1) and Juan A. Melero *(C) \\ Chemical and Environmental Engineering Group, Escuela Superior de Ciencias Experimentales y \\ Tecnología (ESCET), Universidad Rey Juan Carlos, 28933 Móstoles, Madrid, Spain \\ * Correspondence: gabriel.morales@urjc.es (G.M.); jose.iglesias@urjc.es (J.I.); juan.melero@urjc.es (J.A.M.)
}

Received: 18 May 2020; Accepted: 20 May 2020; Published: 22 May 2020

Biomass, in its many forms-oils and fats, lignocellulose, algae, etc.-is widely contemplated as a potential alternative to dwindling fossil fuel reserves, as its enormous and widespread availability allows for its consideration as a source for biofuels and a wide range of bio-based chemicals. The search for new sustainable and efficient alternatives to fossil feedstock is gaining increasing relevance within the chemical industry, wherein the role of catalysis is often critical for the development of clean and sustainable processes, with a high efficiency and atom economy [1]. In transportation, the penetration of biofuels has reached so far just modest figures because of a number of limitations associated to the so-called first-generation biofuels (mainly ethanol from sugars containing plants or cereal crops, and biodiesel from edible vegetable oils). Accordingly, the development of new types of biofuels has been identified as an urgent need. Likewise, the term "advanced biofuels" has spread to refer to biofuels that comply with sustainability criteria and do not compete with the food market. They should be produced preferentially from forestry and agriculture residues, non-food energy crops, industrial wastes and other non-conventional sources, such as microalgae and microorganisms. This scheme is expected to exhibit many benefits, as it would allow combining the large-scale production of biofuels, accompanied by a significant reduction of greenhouse gases emissions, with an efficient management and valorisation of different types of biomass wastes. The biorefinery concept has been envisaged to integrate within a single facility the upgrading of different raw materials (biomass and wastes) into transportation fuels, chemicals and energy. Noticeably, a relatively small number of platform chemicals has been identified and proposed as key intermediates to the final target products.

The main routes for the conversion and valorisation of biomass are sorted according to its chemical nature. For lipids and oils, the main routes are transesterification, catalytic cracking and hydrotreatment to produce different types of biofuels within the gasoline and diesel range. Transesterification remains the main catalytic route for the production of fatty acid alkyl esters as a replacement for diesel fuel [2]. Catalytic cracking and hydrocracking present the advantage of leading to higher liquid fuels yield. Numerous examples can be found in the literature about the use of heterogeneous catalysts for both types of transformations. A key aspect of these catalysts is their ability to remove oxygen contained in the oleaginous feedstock by decarboxylation, decarbonylation, dehydration and hydrodeoxygenation reactions, usually requiring the incorporation of metal species to an acidic solid support [3].

The major route currently in use for the conversion of sugar carbohydrates is the combination of enzymatic saccharification and fermentation treatments to produce alcohols, mainly ethanol. In contrast, when using lignocellulosic biomass, a large variety of alternative processes are possible, such as gasification (usually combined with Fisher-Tropsch synthesis), pyrolysis, liquefaction, hydrolysis and aqueous phase reforming. Moreover, aqueous sugars may be catalytically upgraded through chemical strategies, usually in the presence of catalysts, to produce platform molecules and bio-based chemicals [4]. The development of efficient processes for the valorisation of lignocellulosic biomass is currently of great relevance, since it would open up the possibility of generating 
valuable bio-products from a great variety of abundant and renewable sources, such as agriculture, pruning and forestry residues, agroindustrial waste or even dedicated non-edible energy crops. For the conversion of lignocellulose, both thermocatalytic and chemocatalytic transformations are envisioned. The former involves the conversion of lignocellulose through a fast pyrolysis process into bio-oil, which is subsequently catalytically upgraded through distinct types of treatments, such as pyrolysis, esterification, ketonization, aldol condensation and hydrodeoxygenation. The chemocatalytic routes mostly start from the sugars obtained by lignocellulose hydrolysis, which can be further transformed by isomerization, dehydration and hydrogenation into different intermediate compounds, usually called platform molecules (e.g., 5-HMF, furfural, levulinic acid, sorbitol, etc.). In turn, such platforms can be converted into a large variety of final products with relevant applications in the formulation of advanced biofuels and/or the commercially valuable chemicals $[5,6]$.

To summarize, there is a wide range of biomass sources, conversion routes and products, where the use of catalysis is of major importance to provide clean and sustainable processes with a high efficiency and atom economy. Although large efforts are worldwide invested in the implementation of heterogeneous catalysts for biomass transformation, results are still less straightforward than initially thought. This is because biomass presents a number of particular features that difficult the development of feasible valorisation processes: (i) biomass typically consists of complex and bulky molecules with multiple functionalities, the processing of which is not an easy task, usually requiring pre-treatments to facilitate the contact catalyst-biomass; (ii) high water content, and consequently hydrothermal conditions, in many cases with non-neutral $\mathrm{pH}$, which may have severe detrimental effects on the catalysts; (iii) aside of carbon and hydrogen, biomass contains significant amounts of heteroatoms like oxygen (reaching values close to $50 \mathrm{wt} \%$ in many biomass components), nitrogen and phosphorus, which typically need to be partially or totally removed to provide the target products; and (iv) formation of carbonaceous deposits through non-desired transformations, due to the complex composition of biomass, making it highly reactive because of the presence of a multitude of components with different functional groups. The development of new catalytic processes, able to perform multifunctional cascade transformations and aiming to process intensification principles, is one of the keys to face these challenges. Classic heterogeneous catalysts need to be tailored for biomass valorisation, especially in terms of enhanced accessibility, tight control of the acidic features, generation of basic sites, surface polarity and the preparation of multifunctional materials by incorporation of metal phases [7].

This Special Issue gathers works at the cutting edge of investigation in application of catalysis for the sustainable conversion of biomass into biofuels and bio-based chemicals. Lignocellulosic biomass attracts most of the attention, with up to eight manuscripts related to this topic. Thus, Huiling Li et al. present a study on the catalytic hydrolysis of lignocellulose over magnetic solid acid in an efficient pathway, where a bamboo-derived carbonaceous magnetic solid acid catalyst was synthesized by $\mathrm{FeCl}_{3}$ impregnation, followed by carbonization and $-\mathrm{SO}_{3} \mathrm{H}$ group functionalization [8]. Xueru Sheng et al. show the use of waste-seashell-derived $\mathrm{CaO}$ catalysts as high-performance solid base catalysts for biomass-derived cyclopentanone self-condensation, which is an important reaction in bio-jet fuel or perfume precursor synthesis [9]. Michèle Besson et al. present the comparative selective catalytic $\mathrm{C}-\mathrm{O}$ bond hydrogenolysis of $\mathrm{C} 5-\mathrm{C} 6$ polyols, sugars, and their mixtures for the production of valuable $\mathrm{C} 6$ and $\mathrm{C} 5$ deoxygenated products over $\mathrm{ReO}_{x}-\mathrm{Rh} / \mathrm{ZrO}_{2}$ catalysts. They show that $\mathrm{C}-\mathrm{O}$ bond cleavage occurs significantly via multiple consecutive deoxygenation steps, leading to the formation of linear deoxygenated C6 or C5 polyols [10]. Elísabet Pires et al. show the application of sulfonated hydrothermal carbons from cellulose and glucose as catalysts for glycerol ketalization. In their work, the sulfonated hydrothermal carbons were also coated on a graphite microfiber felt (SHTC@GF), and they report the first results on the continuous flow production of solketal [11]. The group of Dr. Anders Riisager contributes with an efficient and selective catalytic method for the aerobic oxidation of lignin and lignin model compounds to aromatics. Particularly, their work relates to the oxidative cleavage catalysed by $\mathrm{Ru} / \mathrm{Al}_{2} \mathrm{O}_{3}$ of a representative lignin model compound, guaiacyl glycerol- $\beta$-guaiacyl ether [12]. Karen Wilson et al. present the acetic acid ketonization 
catalysed by Ga/HSM-5 for the upgrading of biomass pyrolysis vapours. Pyrolysis bio-oils contain significant amounts of carboxylic acids, which limit their utility as biofuels. Ketonisation of carboxylic acids within biomass pyrolysis vapours is a potential route to upgrade the energy content and stability of the resulting bio-oil condensate, but requires active, selective and coke-resistant solid acid catalysts. In their work, Ga-doped HZSM-5 exhibited good stability for over five $\mathrm{h}$ on-stream acetic acid ketonization [13]. The group of Dr. Robert A. Dagle analyses the viability of using a $\mathrm{Zn}_{\mathrm{x}} \mathrm{Zr}_{\mathrm{y}} \mathrm{O}_{\mathrm{z}}$ mixed oxide catalyst for the direct production of $\mathrm{C} 4$ olefins from the aqueous phase derived from three different bio-oils. Complete conversion of the carboxylic acids was achieved over said catalyst for all the feedstocks investigated, being the main reaction product isobutene ( $>30 \%$ selectivity) [14]. Pedro Maireles-Torres et al. have contributed with a work about the selective conversion of glucose into HMF using L-type zeolites with different morphologies, where they also show that the addition of $\mathrm{CaCl}_{2}$ has a positive influence on the catalytic performance [15].

Within the field of biodiesel and oleaginous feedstock, Ching-Chang Chen et al. present the use of bauxite as a low-cost solid base catalyst precursor for the production of biodiesel via transesterification. Bauxite is economic, contains a high percentage of $\mathrm{Si}$ and $\mathrm{Al}$ species, and can replace expensive commercial materials [16]. Likewise, Mark Crocker et al. have demonstrated the promotional effect of $\mathrm{Cu}, \mathrm{Fe}$ and $\mathrm{Pt}$ on the performance of $\mathrm{Ni} / \mathrm{Al}_{2} \mathrm{O}_{3}$ in the deoxygenation of used cooking oil to fuel-like hydrocarbons [17].

Finally, Xiaohui Zhang et al. make an evaluation on the methane production potential of wood waste pre-treated with $\mathrm{NaOH}$ and co-digested with pig manure, to provide an effective method to apply wood waste in anaerobic digestion [18]. Last, but not least, Dr. Zhou \& Dr. Hu provide a comprehensive review analysing the catalytic thermochemical conversion of algae and upgrading of algal oil for the production of high-grade liquid fuel [19].

In conclusion, we personally feel that the present Special Issue "Sustainable Catalytic Conversion of Biomass for the Production of Biofuels and Bioproducts" is of great interest and relevance, as it covers many of the new aspects of catalysis applied to biomass, and significantly contribute to further development in this field. We are honoured to have been Guest Editors for this issue, and would like to thank all the contributors and reviewers for providing us with their valuable manuscripts and comments. We are also grateful to Keith Hohn, the Editor-in-Chief, and all the staff of the Catalysts Editorial Office.

Conflicts of Interest: The authors declare no conflict of interest.

\section{References}

1. Aricò, F.; Moreno-Tost, R. Editorial Overview: Editorial: Toward new sustainable development goals. Curr. Opin. Green Sustain. Chem. 2020, A1-A3. [CrossRef]

2. Thangaraj, B.; Solomon, P.R.; Muniyandi, B.; Ranganathan, S.; Lin, L. Catalysis in biodiesel production-A review. Clean Energy 2019, 3, 2-23. [CrossRef]

3. Kim, S.; Kwon, E.E.; Kim, Y.T.; Jung, S.; Kim, H.J.; Huber, G.W.; Lee, J. Recent advances in hydrodeoxygenation of biomass-derived oxygenates over heterogeneous catalysts. Green Chem. 2019, 21, 3715-3743. [CrossRef]

4. Mika, L.T.; Cséfalvay, E.; Németh, Á. Catalytic Conversion of Carbohydrates to Initial Platform Chemicals: Chemistry and Sustainability. Chem. Rev. 2018, 118, 505-613. [CrossRef] [PubMed]

5. Costa, F.F.; de Oliveira, D.T.; Brito, Y.P.; da Rocha Filho, G.N.; Alvarado, C.G.; Balu, A.M.; Luque, R.; Nascimento, L.A.S. Do Lignocellulosics to biofuels: An overview of recent and relevant advances. Curr. Opin. Green Sustain. Chem. 2020, 24, 21-25. [CrossRef]

6. Arias, P.L.; Cecilia, J.A.; Gandarias, I.; Iglesias, J.; López Granados, M.; Mariscal, R.; Morales, G.; Moreno-Tost, R.; Maireles-Torres, P. Oxidation of lignocellulosic platform molecules to value-added chemicals using heterogeneous catalytic technologies. Catal. Sci. Technol. 2020, 10, 2721-2757. [CrossRef]

7. Serrano, D.P.; Melero, J.A.; Morales, G.; Iglesias, J.; Pizarro, P. Progress in the design of zeolite catalysts for biomass conversion into biofuels and bio-based chemicals. Catal. Rev. Sci. Eng. 2018, 60, 1-70. [CrossRef]

8. Zhu, Y.; Huang, J.; Sun, S.; Wu, A.; Li, H. Effect of dilute acid and alkali pretreatments on the catalytic performance of bamboo-derived carbonaceous magnetic solid acid. Catalysts 2019, 9, 245. [CrossRef] 
9. Sheng, X.; Xu, Q.; Wang, X.; Li, N.; Jia, H.; Shi, H.; Niu, M.; Zhang, J.; Ping, Q.W. Waste seashells as a highly active catalyst for cyclopentanone self-aldol condensation. Catalysts 2019, 9, 661. [CrossRef]

10. Mounguengui-Dialo, M.; Sadier, A.; Noly, E.; Perez, D.D.S.; Pinel, C.; Perret, N.; Besson, M. C-O bond hydrogenolysis of aqueous mixtures of sugar polyols and sugars over ReOx-Rh/ZrO2 catalyst: Application to an hemicelluloses extracted liquor. Catalysts 2019, 9, 740. [CrossRef]

11. Fernández, P.; Fraile, J.M.; García-Bordejé, E.; Pires, E. Sulfonated hydrothermal carbons from cellulose and glucose as catalysts for glycerol ketalization. Catalysts 2019, 9, 804. [CrossRef]

12. Melián-Rodríguez, M.; Saravanamurugan, S.; Meier, S.; Kegnæs, S.; Riisager, A. Ru-catalyzed oxidative cleavage of guaiacyl glycerol- $\beta$-guaiacyl ether-a representative $\beta$-O-4 lignin model compound. Catalysts 2019, 9, 832. [CrossRef]

13. Jahangiri, H.; Osatiashtiani, A.; Ouadi, M.; Hornung, A.; Lee, A.F.; Wilson, K. Ga/HZSM-5 catalysed acetic acid ketonisation for upgrading of biomass pyrolysis vapours. Catalysts 2019, 9, 841. [CrossRef]

14. Davidson, S.D.; Lopez-Ruiz, J.A.; Flake, M.; Cooper, A.R.; Elkasabi, Y.; Morgano, M.T.; Dagle, V.L.; Albrecht, K.O.; Dagle, R.A. Cleanup and conversion of biomass liquefaction aqueous phase to C3-C5 olefins over ZnxZryOz catalyst. Catalysts 2019, 9, 923. [CrossRef]

15. Ginés-Molina, M.J.; Ahmad, N.H.; Mérida-Morales, S.; García-Sancho, C.; Mintova, S.; Ng, E.P.; Maireles-Torres, P. Selective conversion of glucose to 5- hydroxymethylfurfural by using L-type zeolites with different morphologies. Catalysts 2019, 9, 1073. [CrossRef]

16. Dai, Y.M.; Hsieh, C.H.; Lin, J.H.; Chen, F.H.; Chen, C.C. Biodiesel production using bauxite in low-cost solid base catalyst precursors. Catalysts 2019, 9, 1064. [CrossRef]

17. Silva, G.C.R.; Qian, D.; Pace, R.; Heintz, O.; Caboche, G.; Santillan-Jimenez, E.; Crocker, M. Promotional effect of $\mathrm{Cu}, \mathrm{Fe}$ and $\mathrm{Pt}$ on the performance of Ni/Al2O3 in the deoxygenation of used cooking oil to fuel-like hydrocarbons. Catalysts 2020, 10, 91. [CrossRef]

18. Li, R.; Tan, W.; Zhao, X.; Dang, Q.; Song, Q.; Xi, B.; Zhang, X. Evaluation on the methane production potential of wood waste pretreated with $\mathrm{NaOH}$ and Co-digested with pig manure. Catalysts 2019, 9, 539. [CrossRef]

19. Zhou, Y.; Hu, C. Catalytic thermochemical conversion of algae and upgrading of algal oil for the production of high-grade liquid fuel: A review. Catalysts 2020, 10, 145. [CrossRef] 